\title{
Social Media Use Continues to Increase Among Orthopaedic Residency Programs in the United States
}

\author{
Muhammad J. Abbas, B.S., Toufic R. Jildeh, M.D., Lafi S. Khalil, M.D., Patrick Buckley, B.S., \\ Salma P. Mumuni, B.S., Kenneth J. Washington, B.S., and Kelechi R. Okoroha, M.D.
}

\begin{abstract}
Purpose: To evaluate the social media usage of orthopaedic residency programs, program directors (PDs), and department chairs across Instagram, Facebook, and Twitter and to determine which types of social media posts are indicative of increased user following. Methods: A systematic online search strategy was performed in October 2020 to identify all allopathic orthopaedic surgery residency program accounts on Instagram, Facebook, and Twitter. Instagram posts were further analyzed to evaluate the type of post that significantly correlated with increased follower counts. Results: Of 158 orthopaedic surgery programs, 69 (43.7\%) had Instagram accounts, $52(32.9 \%)$ had Facebook accounts, and 54 (34.2\%) had Twitter accounts. Program presence on Instagram and Twitter continued to grow exponentially $\left(R^{2}=0.99\right.$ and $R^{2}=0.95$, respectively). Regarding program leadership, a total of 151 PDs and 156 chairs were identified. Of these, 21 PDs ( $14 \%)$ and 8 chairs $(5.1 \%)$ had Instagram accounts. The number of posts and the numbers of educational, social, program information, and operative posts $(P<.01)$ significantly correlated with increased followers on Instagram. Conclusions: Fewer than one-half of orthopaedic surgery residency programs and fewer than one-quarter of PDs and department chairs have a social media presence. However, the number of residency programs on social media continues to rise year-over-year. The total number of posts; the amount of educational, social, and program information; and the number of operative posts significantly correlated with increased followers on Instagram. Clinical Relevance: With the growing prevalence of social media, orthopaedic surgery residency programs have the opportunity to connect with future applicants and disseminate informational content regarding their programs.
\end{abstract}

$\mathbf{T}$ The accessibility of the internet has facilitated the rapid growth of social media and has created a new way for individuals to connect. Over half the global population now uses social media, and the average internet user has 8 unique social media accounts. ${ }^{1}$

From the Department of Orthopaedic Surgery, Henry Ford Hospital, Detroit, Michigan, U.S.A. (M.J.A., T.R.J., P.B., L.S.K.); Wayne State University School of Medicine, Detroit, Michigan, U.S.A. (S.P.M., K.J.W.); and Department of Orthopedic Surgery, Mayo Clinic, Rochester, Minnesota, U.S.A. (K.R.O.).

The authors report the following potential conflicts of interest or sources of funding: K.R.O. receives hospitality payments from Stryker and Zimmer and receives education support from Arthrex and Smith $\theta$ Nephew, outside the submitted work. Full ICMJE author disclosure forms are available for this article online, as supplementary material.

Received April 10, 2021; accepted August 13, 2021.

Address correspondence to Muhammad J. Abbas, B.S., Department of Orthopaedic Surgery, Henry Ford Hospital, 2799 W Grand Blvd, Detroit, MI 48202,U.S.A.E-mail:mabbas5@hfhs.org

(C) 2021 THE AUTHORS. Published by Elsevier Inc. on behalf of the Arthroscopy Association of North America. This is an open access article under the CC BY-NC-ND license (http://creativecommons.org/licenses/by-nc-nd/4.0/).

2666-061X/21519

https://doi.org/10.1016/j.asmr.2021.08.004
Social media usage is growing at an exponential rate, and a younger demographic is leading the trend, with $90 \%$ of individuals aged 18 to 29 years using at least 1 social media site. ${ }^{2}$ The rapid adoption of social media has led to its use across multiple fields, including medicine.

As social media has evolved into a more common platform to disseminate information, multiple studies have been performed to assess its usage by health care providers. ${ }^{3-5}$ Additionally, many studies have investigated the social media presence of residency programs across different specialties including otolaryngology, neurosurgery, radiology, and urology. ${ }^{6-9}$ According to a study examining orthopaedic residency applicants, $85 \%$ of applicants are under 29 years old, indicating that orthopaedic residency applicants are part of the age demographic with the most active social media presence. ${ }^{2,10}$ Furthermore, the emergence of SARS-COV-2 (severe acute respiratory syndrome coronavirus 2 ) in 2020 created new challenges for residency programs looking to garner interest from potential applicants. Because of the pandemic, visiting rotations and in-person interviews were canceled, thus restricting applicant travel 
and familiarity with programs outside the home institution. In an effort to facilitate medical student interest, many residency programs turned to social media as a recruitment modality.

Given the increasing usage of social media platforms and the challenges of the 2020-2021 application cycle, an assessment of the state of American orthopaedic surgery residency programs' social media presence was conducted. ${ }^{2,10,11}$ The purposes of this study were to evaluate the social media usage of orthopaedic residency programs, program directors (PDs), and department chairs across Instagram (Facebook, Menlo Park, CA), Facebook, and Twitter (San Francisco, CA) and to determine which types of social media posts are indicative of increased user following. It was hypothesized that most programs would not have a social media presence and that a large number of programs would be seen beginning to use social media platforms in 2020 .

\section{Methods}

To gauge the online footprint of orthopaedic surgery residencies, a comprehensive search strategy was used to determine the extent of social media use among allopathic orthopaedic surgery residency programs. A total of 158 orthopaedic surgery residency programs were identified for inclusion based on the Association of American Medical Colleges electronic residency application service data from 2019. A systematic online search strategy was used in October 2020 to identify all accounts on Instagram, Facebook, and Twitter that were relevant orthopaedic accounts. Instagram, Facebook, and Twitter were searched for accounts belonging to the program, department chairperson (chair), and residency PD. As performed in previous studies, social media accounts were identified by searching combinations of full and abbreviated program names in addition to the following terms: orthopedic surgery, orthopedics, orthopaedics, or ortho. ${ }^{12,13}$ An up-to-date repository of residency PDs and chairpersons was collected through a combination of Doximity (San Francisco, CA), LinkedIn (Mountain View, CA), and program websites. Social media platforms were searched to identify PDs and chairs. For every social media account found, the followers were investigated for similar accounts to further maximize the number of program accounts identified. Additionally, the social media accounts of program leadership were stratified into 1 of 3 categories based on the predominant type of content posted on the account: professional, personal, or mixed. Professional accounts predominantly included posts related to orthopaedic surgery, patient care, and education. Personal accounts predominantly featured posts regarding individuals' personal lives, family, and lifestyle. Mixed accounts lacked a predominant post type and showed features of both the professional and personal categories. Account type was determined by 2 individual observers, and
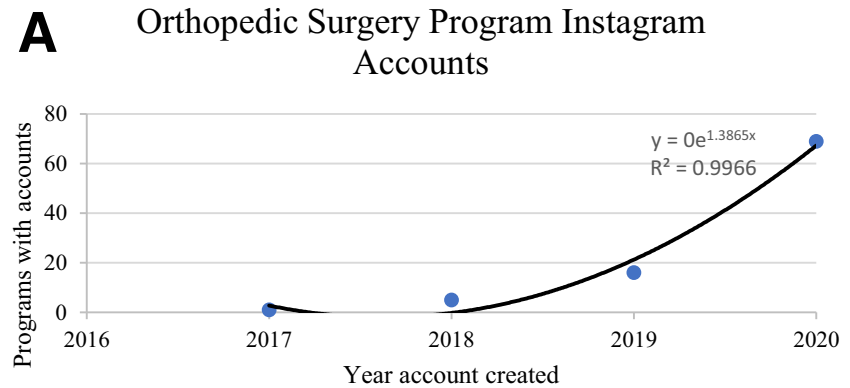

B Orthopedic Surgery Programs with Facebook Accounts

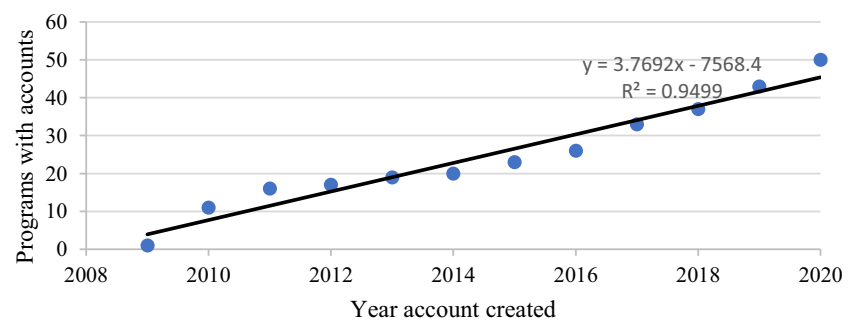

C Orthopedic Surgery Programs with Twitter Accounts

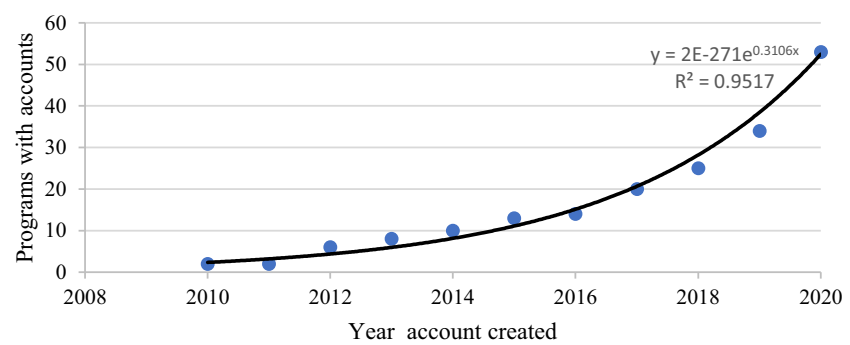

Fig 1. Total number of allopathic orthopaedic residency programs each year with accounts on Instagram (A), Facebook (B), and Twitter (C). The trend lines show exponential growth $\left(R^{2}=0.99\right)$ for Instagram, linear growth $\left(R^{2}=0.95\right)$ for Facebook, and exponential growth for Twitter $\left(R^{2}=0.95\right)$.

mutual agreement was reach on all accounts. To determine the rank of orthopaedic surgery residency programs, US News $\theta$ World Report residency rankings were used. ${ }^{14}$

\section{Instagram Analysis}

The evaluation of social media posts has been performed in previous studies. ${ }^{12,13}$ The total number of posts is provided on the Instagram page of given accounts. Posts were categorized as educational, operative, social, informational, self-promotional, visiting lecturer, research, and other (Appendix Table 1). The educational label was applied if the post described a technique or promoted specific orthopaedic knowledge. Any photograph taken within the confines of an operating room was considered operative. Informational posts highlighted program features, training, or updates on matching, as well as faculty and resident 
Table 1. Distribution of Chairperson Accounts

\begin{tabular}{lclr}
\hline & Professional & Mixed & Personal \\
\hline Facebook $(\mathrm{n}=9)$ & $1(11 \%)$ & $1(11 \%)$ & $7(78 \%)$ \\
Twitter $(\mathrm{n}=17)$ & $0(0 \%)$ & $1(6 \%)$ & $16(94 \%)$ \\
Instagram $(\mathrm{n}=8)$ & $5(63 \%)$ & $1(13 \%)$ & $2(25 \%)$ \\
\hline
\end{tabular}

spotlights. The self-promotional label was used to describe posts consisting of advertising or marketing for the program designed to recruit or elevate the program. Posts were designated to the category of visiting lecturer when a photograph or caption highlighting a visiting professor presentation or faculty member presentation was posted. Research posts included presentations of research at a conference, screenshots of publications, discussions of recent publications, or journal-club events. All other posts were categorized as other. Four authors (M.J.A., P.B., S.P.M., and K.J.W.) independently conducted all searches and extracted data. Disagreements between reviewers were resolved by consensus.

\section{Statistical Analysis}

All continuous variables were expressed as mean \pm standard deviation, and all categorical variables were expressed as counts and column percentages. Regression analyses were used to describe the rate of growth in social media accounts for orthopaedic surgery programs over time. Wilcoxon rank sum analysis was used for comparison among program rankings to evaluate factors influencing numbers of followers. Analysis of all data was performed using SAS software (version 9.4; SAS Institute, Cary, NC). Statistical significance was set as $P<.05$.

\section{Results}

Of the 158 programs identified for inclusion, as of October 2020, 69 (43.7\%) had Instagram accounts, 52 $(32.9 \%)$ had Facebook accounts, and $54(34.2 \%)$ had Twitter accounts. Although the cumulative use of all 3 social media platforms by orthopaedic surgery programs is growing annually (Fig 1), program presence on Instagram and Twitter grew exponentially $\left(R^{2}=0.99\right.$ and $R^{2}=0.95$, respectively) whereas Facebook showed a linear growth rate $\left(R^{2}=0.94\right)$. The mean number of total tweets per program was $478 \pm 951$, and the mean number of followers per program was $596 \pm 1,305$. For Instagram, the mean number of total posts per program was $45 \pm 12$, and the mean number of followers per program was $796 \pm 460$. Of note, in 2020 (COVID-19 [coronavirus disease 2019] pandemic), 53 programs created an Instagram account. Of the 53 new Instagram accounts, $62 \%$ were the first social media account of the program.

Regarding program leadership, a total of 151 PDs and 156 chairs were identified. Of these, 21 PDs (14\%) and 8 chairs $(5.1 \%)$ had Instagram accounts; 51 PDs
$(32.3 \%)$ and 9 chairs $(5.7 \%)$ had Facebook accounts; and 25 PDs (15.8\%) and 17 chairs $(10.8 \%)$ had Twitter accounts (Tables 1 and 2).

Further analysis of Instagram accounts revealed that on average, programs were mostly posting informational content specific to their training program $(23 \%)$ and social photographs $(23 \%)$, followed by promotional $(15 \%)$, educational $(14 \%)$, operative $(5 \%)$, research or conference $(3 \%)$, and visiting lecturer $(1 \%)$ posts (Fig 2). When we evaluated factors that influenced the number of followers, linear regression models showed that the total number of posts $(P<.01)$ and the numbers of educational $(P<.01)$, surgical $(P<.01)$, social $(P<.01)$, program information $(P<.01)$, program promotional $(P<.01)$, and guest lecturer $(P<.01)$ posts all had significant correlations with increased follower count (Table 3). The number of accounts a program followed $(P=.15)$ and the number of posts related to research $(P=.63)$, as well as posts classified as other $(P=.9)$, had no significant relation with follower count. Furthermore, programs affiliated with hospitals ranked in the top 10 by US News $\theta$ World Report had more followers on average than those not in the top 10; however, this difference was not significant $(1,022.6 \pm 500.47$ vs $778.88 \pm 455.85, P=.34)$.

\section{Discussion}

Although social media has become increasingly prevalent in our society, our study found that fewer than half of all allopathic orthopaedic surgery residency programs and fewer than a quarter of PDs and department chairpersons had a social media presence. However, it was shown that the number of programs on social media continues to rise year after year. Programs have favored posting content geared toward informing viewers about their programs, operative experiences, and social interactions between residents and faculty. The total number of posts and the numbers of educational, social, program information, and operative posts all had a significant correlation with an increased follower count on Instagram.

With the growing popularity of social media among prospective residency applicants and within the general population, several studies have sought to evaluate the social media presence of medical residency programs on such platforms. In a retrospective review of the online presence of 126 allopathic dermatology residency programs, St Claire et al. ${ }^{15}$ found that in 2019 , only $23 \%$ were present on Facebook; 11\%, on Twitter; and 7\%,

Table 2. Distribution of Program Director Accounts

\begin{tabular}{lclc}
\hline & Professional & Mixed & Personal \\
\hline Facebook $(\mathrm{n}=43)$ & $2(5 \%)$ & $2(5 \%)$ & $39(90 \%)$ \\
Twitter $(\mathrm{n}=25)$ & $20(80 \%)$ & $4(16 \%)$ & $1(4 \%)$ \\
Instagram $(\mathrm{n}=21)$ & $4(19 \%)$ & $9(43 \%)$ & $8(38 \%)$ \\
\hline
\end{tabular}




\section{Type of Posts by Orthopedic Surgery Training Programs on Instagram}

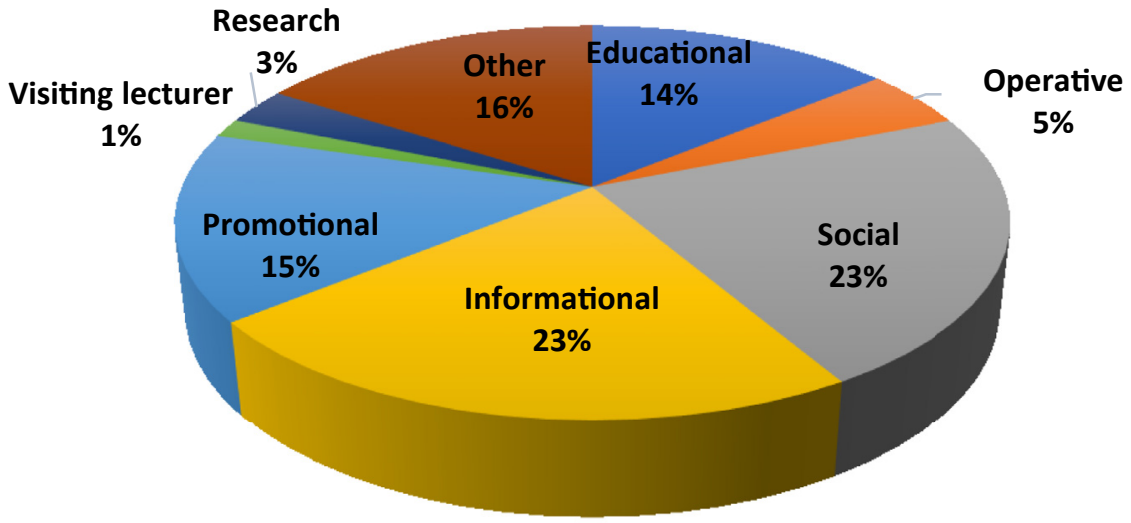

Fig 2. Distribution of posts on Instagram accounts of allopathic orthopaedic surgery residency programs.

on Instagram. Additionally, Xie et al. ${ }^{6}$ examined the presence of 101 otolaryngology residency programs in 2017 and found that only $29.7 \%$ had some form of social media. Only $13.9 \%$ and $24.8 \%$ had a presence on Twitter and Facebook, respectively. In an analysis of 73 plastic surgery residency programs conducted from 2010 to 2019, Azoury et al. ${ }^{16}$ found that $56.8 \%$ of programs had an account on Instagram, $30.5 \%$ had an account on Facebook, and $28.4 \%$ had a Twitter account. Furthermore, they showed a rate of exponential growth $\left(R^{2}=0.97\right)$ in the number of Instagram accounts created year-over-year. Our study found that among the 158 allopathic orthopaedic surgery residency programs, $43.7 \%$ have Instagram accounts, $32.9 \%$ have Facebook accounts, and $34.2 \%$ have Twitter accounts. These findings indicate that orthopaedic surgery residency programs have a similar social media footprint to other surgical specialties and variance between specialties can likely be attributed to the year in which the study was conducted, given that the social media presence of programs continues to grow globally among residencies. Additionally, the number of Instagram and Twitter accounts increased exponentially year-over-year, with 53 new Instagram accounts being created in 2020. The rapid increase in the number of accounts in 2020 is likely attributed to the impact of the COVID-19 pandemic on medical education. Pandemic guidelines called for the suspension of visiting rotations for prospective residency candidates and a shift to virtual interviews. This caused programs to use social media to inform prospective candidates about their programs and overcome the lack of a physical presence with candidates. ${ }^{17}$

Previous studies have sought to evaluate the ways programs can use social media most effectively. Bhayani et al. ${ }^{18}$ put together guidelines for how residency programs can best use social media. They highlighted the importance of sharing the accomplishments of a trainee and the program, conveying a culture of learning, and sharing lifestyle and social interactions. Azoury et al. ${ }^{16}$ examined the types of Instagram content and their correlation with higher follower counts in plastic surgery. They found that the total number of posts $(P<.01)$, the number of surgical posts $(P<.01)$, the number of social interaction posts $(P<.01)$, and the number of posts offering information about the program $(P<.01)$ were all significantly correlated with an increased follower count. In agreement with these studies, our investigation found that among the Instagram accounts of orthopaedic surgery residency programs, the total number of posts and the numbers of educational, surgical, social, and program information posts $(P<.01)$ all had significant correlations with increased follower count. It has been previously shown that prospective surgical residency applicants value high operative volume, faculty

Table 3. Linear Regression of Followers Relative to Program Account Variables

\begin{tabular}{lcrcr}
\hline \multicolumn{1}{c}{ Variable } & Coefficient & SE & $P$ Value & $R^{2}$ \\
\hline No. of accounts program follows & 56.96 & 85.72 & .15 & 0.05 \\
Total posts & 50.78 & 0.86 & $<.01^{*}$ & 0.24 \\
No. of educational posts & 55.32 & 4.41 & $<.01^{*}$ & 0.09 \\
No. of surgical posts & 54.27 & 15.78 & $<.01^{*}$ & 0.13 \\
No. of social posts & 43.64 & 3.04 & $<.01^{*}$ & 0.44 \\
No. of program information posts & 54.27 & 4.11 & $<.01^{*}$ & 0.13 \\
No. of promotional posts & 54.58 & 4.65 & $<.01^{*}$ & 0.12 \\
No. of visiting lecturer posts & 50.69 & 27.15 & $<.01^{*}$ & 0.24 \\
No. of research posts & 58.05 & 15.68 & .63 & $<0.01$ \\
No. of other posts & 54.93 & 3.05 & .09 & 0.04 \\
\hline
\end{tabular}

SE, standard error

${ }^{*}$ Statistically significant $(P<.05)$. 
mentorship, and resident happiness, and it should therefore be no surprise that content speaking to these attributes likely contributes to increased follower count and appeal to prospective program applicants. ${ }^{19}$ The number of posts regarding research and the number of followed accounts did not correlate with increases in follower count. These findings suggest that posts regarding research and the number of accounts followed do not necessarily lead to an increased number of followers.

Aside from evaluating the social media presence of residency programs, it was also important to examine usage by PD and department chairs because these roles play an important part in shaping programs. Azoury et al. ${ }^{16}$ found that among plastic surgery residency PDs, only $23.2 \%$ had an Instagram account, $32.6 \%$ had a Facebook account, and $15.8 \%$ had a Twitter account. They found that among department chairs, $21.1 \%$ had an Instagram account, $35.8 \%$ had a Facebook account, and $20 \%$ had a Twitter account. Facebook was the most common platform, with most accounts being personal ones (67\% for PDs and 63\% for department chairs). Our study found that among orthopaedic surgery PDs, only $13.3 \%$ had an Instagram account, $32.3 \%$ had a Facebook account, and $15.8 \%$ had a Twitter account. Among department chairs, $5.1 \%$ had an Instagram account, $5.7 \%$ had a Facebook account, and $10.8 \%$ had a Twitter account. Although our results are in agreement with previous findings within plastic surgery residency department leadership, it is apparent that there is little involvement of program leadership on social media. Further involvement on social media would provide program leadership with a platform to garner more interest from applicants into their respective programs while also providing a means of information sharing between the members of leadership of various programs.

\section{Limitations}

There are several limitations present in this study. A limitation inherent to the cross-sectional nature of this analysis is that the data were collected at a single time point and, for this reason, we cannot account for posts that were previously posted but have since been deleted. Analysis of post types that influenced follower count was limited to Instagram posts. The reason for this is that Instagram is the most popular social media platform used by residency programs. It should also be noted that when an Instagram post did not clearly fit into a described category, mutual agreement by reviewers was used to determine which category was best. Owing to the retrospective nature of this study, post data analyzed were limited to photographs, videos, and text posted on Instagram accounts. Instagram Stories were not included in this analysis because of their transient nature of only being present on the account for 24 hours before being deleted. This made it impossible to retrospectively evaluate the impact of this type of post. It must be noted that the study period was over a relatively short time span; however, this was because of social media only being used by programs beginning in 2010. In the evaluation of Twitter posts, the large variability in the number of tweets and followers is likely because of diminished usage of the platform by certain programs and is to be expected on any social media platform.

\section{Conclusions}

Fewer than one-half of orthopaedic surgery residency programs and fewer than one-quarter of PDs and department chairs have a social media presence. However, the number of residency programs on social media continues to rise year-over-year. The total number of posts; the amount of educational, social, and program information; and the number of operative posts significantly correlated with increased followers on Instagram.

\section{References}

1. Kemp S. Digital 2020: July global statshot, https:// datareportal.com/reports/digital-2020-july-global-statshot. Accessed August 8, 2021.

2. Pew Research Center. Social media fact sheet, https:// www.pewresearch.org/internet/fact-sheet/social-media/. Accessed August 8, 2021.

3. Surani Z, Hirani R, Elias A, et al. Social media usage among health care providers. BMC Res Notes 2017;10:654.

4. Mondkar A, Scambler S, Gallagher JE. Hashtag, like or tweet: A qualitative study on the use of social media among dentists in London [published online February 24, 2021]. Br Dent J. 10.1038/s41415-021-2655-2.

5. Almaiman S, Bahkali S, Al Farhan A, Bamuhair S, Househ M, Alsurimi K. The prevalence of using social media among healthcare professionals in Saudi Arabia: A pilot study. Stud Health Technol Inform 2015;213:263-266.

6. Xie DX, Dedmon MM, O'Connell BP, Yawn RJ, Haynes DS. Evaluation of social media presence of otolaryngology residency programs in the United States. JAMA Otolaryngol Head Neck Surg 2018;144:802-806.

7. Alotaibi NM, Badhiwala JH, Nassiri F, et al. The current use of social media in neurosurgery. World Neurosurg 2016;88:619-624.e7.

8. Glover M, Choy G, Boland GW, Saini S, Prabhakar AM. Radiology and social media: Are private practice radiology groups more social than academic radiology departments? J Am Coll Radiol 2015;12:513-518.

9. Ciprut S, Curnyn C, Davuluri M, Sternberg K, Loeb S. Twitter activity associated with U.S. News and World Report reputation scores for urology departments. Urology 2017;108:11-16.

10. Finkler ES, Fogel HA, Kroin E, et al. Factors influencing the number of applications submitted per applicant to orthopedic residency programs. Med Educ Online 2016;21: 31865.

11. AlFaris E, Irfan F, Ponnamperuma G, et al. The pattern of social media use and its association with academic 
performance among medical students. Med Teach 2018;40: S77-S82.

12. Chandawarkar AA, Gould DJ, Stevens WG. Insta-grated plastic surgery residencies: The rise of social media use by trainees and responsible guidelines for use. Aesthet Surg J 2018;38:1145-1152.

13. Irwin TJ, Riesel JN, Ortiz R, Helliwell LA, Lin SJ, Eberlin KR. The impact of social media on plastic surgery residency applicants. Ann Plast Surg 2021;86:335-339.

14. US News \& World Report. Best hospitals for orthopaedics, https://health.usnews.com/best-hospitals/rankings/ orthopedics. Accessed August 8, 2021.

15. St Claire KM, Rietcheck HR, Patel RR, Dellavalle RP. An assessment of social media usage by dermatology residency programs. Dermatol Online J 2019;25:5.
16. Azoury SC, Mazzaferro DM, Piwnica-Worms W, et al. An update on social media in academic plastic surgery training programs: The rising trend of likes, shares, and retweets. Ann Plast Surg 2020;85:100-104.

17. Boyd CJ, Inglesby DC, Corey B, et al. Impact of COVID-19 on away rotations in surgical fields. J Surg Res 2020;255: 96-98.

18. Bhayani RK, Fick L, Dillman D, Jardine DA, Oxentenko AS, O'Glasser A. Twelve tips for utilizing residency program social media accounts for modified residency recruitment. MedEdPublish 2020;9.

19. Atashroo DA, Luan A, Vyas KS, et al. What makes a plastic surgery residency program attractive? An applicant's perspective. Plast Reconstr Surg 2015;136: 189-196. 
Appendix Table 1. Instagram Post Content Classification System

\begin{tabular}{|c|c|}
\hline Content Topic & Description \\
\hline Educational posts & $\begin{array}{l}\text { Posts trying to teach a concept, announcing } \\
\text { seminars or learning opportunities, or } \\
\text { presenting physical examination findings } \\
\text { and demonstrations }\end{array}$ \\
\hline OR image posts & Posts of images in the OR \\
\hline Social posts & $\begin{array}{l}\text { Posts regarding vacations, hobbies, luxury } \\
\text { items, food, sporting events, concerts, or } \\
\text { festivals }\end{array}$ \\
\hline Informational posts & $\begin{array}{l}\text { Posts providing information about the } \\
\text { residency program }\end{array}$ \\
\hline Self-promotion posts & $\begin{array}{l}\text { Advertisement-style posts about clinical } \\
\text { practice targeted toward patients or } \\
\text { program "advertising" }\end{array}$ \\
\hline Visiting lecturer posts & $\begin{array}{l}\text { Any post making mention of a guest speaker } \\
\text { or visiting lecturer }\end{array}$ \\
\hline Research posts & $\begin{array}{l}\text { Posts regarding publications, abstracts, } \\
\text { posters, conferences, research awards, or } \\
\text { grants }\end{array}$ \\
\hline Other posts & $\begin{array}{l}\text { Posts not specified in aforementioned } \\
\text { categories }\end{array}$ \\
\hline
\end{tabular}

OR, operating room. 